\title{
GÊNERO, SEXUALIDADE E EDUCAÇÃO INFANTIL: MEMORIAL DE FORMAÇÃO满
}

\author{
Gender, sexuality, and childhood education: a formation memorial
}

Género, sexualidad y educación infantil: memorial de formación

Míria Izabel Campos*

\begin{abstract}
Resumo
Em tempos de grandes retrocessos nas conquistas que já se tinham e/ou acreditavam-se como garantidas em nosso país, ter a oportunidade de socializar o que se tem construído acerca de gênero e sexualidade na interação com a Educação Infantil, torna-se extremamente importante e necessário. Sendo assim, dar visibilidade ao memorial de formação da autora, trazendo a trajetória de trabalho com professoras é objetivo deste artigo, pois ele tratará dos caminhos e escolhas implicados nas diversas dimensões que nos formam e (con)formam. À luz do referencial teórico elisiano e da abordagem (auto)biográfica em suas interfaces com o campo educativo, pretende-se descrever e dialogar acerca das desigualdades socialmente construídas, buscando contribuir para o respeito à alteridade. Concluindo, ressalta-se, a partir dos trabalhos apresentados, a importância da realização de mais pesquisas relacionadas à temática em questão, bem como a necessidade de se prosseguir com estudos sobre gênero e sexualidade na formação docente, possibilitando ampliar discussões e debates nos diferentes contextos de educação, da comunidade e demais espaços sociais. Ou seja, entende-se como fundamental continuar a escrita da História da Educação, a partir de outros olhares, possibilitando outros fazeres.
\end{abstract}

PALAVRAS-CHAVE: Processo Civilizador. Abordagem (Auto)biográfica. História da Educação.

\begin{abstract}
In times of great setbacks in the achievements we already had, and/or believed to have had as a guarantee in our country, it is extremely important and necessary to have the opportunity to share what has been studied in terms of gender and sexuality in interaction with Childhood Education. Thus, the purpose of this article is to give visibility to the author's formation memorial, bringing up her work history with teachers. It will deal with the ways and choices involved in the several dimensions that form and (con)form us. In the light of the elisiano theoretical framework and the (auto) biographic approach in its interfaces with the education field, our goal is to describe and dialogue with socially constructed inequalities, aiming to contribute to the respect for otherness. In conclusion, we emphasize, with the works presented, the importance to not only conduct more research related to this topic, but also the need to continue with studies about gender and sexuality in the teacher's career development, making it
\end{abstract}

\footnotetext{
* Este artigo se constituiu a partir da minha Tese de Doutorado intitulada "Tempos de escritas: memoriais de infầncia, docência e gênero", desenvolvida sob a orientação da Professora Doutora Magda Sarat. A defesa aconteceu em 10 de abril de 2018, pelo Programa de Pós-Graduação em Educação (PPGEdu) da Faculdade de Educação (FAED), da Universidade Federal da Grande Dourados (UFGD).

* Doutora em Educação pela Universidade Federal da Grande Dourados (UFGD). Professora Adjunta na mesma Universidade. Vice-líder do Grupo de Pesquisa Educação e Processo Civilizador (GPEPC). Email: miriacampos@ufgd.edu.br
} 
possible to expand discussions and debates in different education contexts, in the communities and other social spaces. In other words, we understand how crucial it is to continue writing the History of Education from other views, enabling other doings.

KEYWORDS: Civilizing process. (Auto)biographic approach. History of Education.

\section{Resumen}

En tiempos de grandes retrocesos de conquistas que ya se tenían y/o se creían garantizadas en nuestro país, tener la oportunidad de socializar lo que se ha construido acerca del género y la sexualidad en la interacción con la Educación Infantil, se hace extremadamente importante y necesario. Así, dar visibilidad al memorial de formación de la autora, sacando a la luz su trayectoria de trabajo con profesoras es el objetivo de este artículo, pues él tratará de los caminos y de las elecciones implicados en las diversas dimensiones que nos forman y nos (con)forman. A la luz del marco teórico de Norbert Elias y del abordaje (auto)biográfico en sus interfaces con el campo educativo, se pretende describir y dialogar acerca de las desigualdades socialmente construidas, buscando contribuir con el respeto a la alteridad. Para concluir, se resalta, desde los trabajos presentados, la importancia de realizarse más investigaciones sobre el tema, así como la necesidad de se proseguir los estudios sobre género y sexualidad en la formación docente, haciendo posible ampliar las discusiones y debates en los diferentes contextos educativos, de la comunidad y demás espacios sociales. O sea, se entiende como fundamental seguir escribiendo acerca de la Historia de la Educación, desde otras miradas, haciendo posibles otros haceres.

PAlAbRAS ClAVE: Proceso de civilización. Abordaje (Auto)biográfica. Historia de la Educación.

\section{INTRODUÇÃO}

Em tempos de grandes retrocessos nas conquistas que já se tinham e/ou acreditavam-se como garantidas em nosso país, ter a oportunidade de socializar o que se tem construído acerca de gênero e sexualidade na interação com a Educação Infantil ${ }^{1}$, torna-se extremamente importante e necessário. Sendo assim, uma das formas que enxergo para tanto, é enaltecer a problematização da questão em tela, ressaltando resistências e enfrentamentos construídos pelos mais distintos movimentos, sejam sociais, acadêmicos e/ou políticos.

Nesse contexto, o objetivo do artigo é dar visibilidade ao meu "memorial de formação" (ABRAHÃO, 2011), pois acreditei que esta publicação [Dossiê Temático "Formação de professores para a infância: história, políticas, diversidade e cultura"] se constitui em oportunidade ímpar. Levando em consideração as falas, discursos e posicionamentos proferidos por diferentes indivíduos, cujas figurações, quase sempre, se constituem e são constituídas por redes de interdependência (ELIAS, 1994) conservadoras, ligadas às mais distintas religiões, ou seja, não fundamentados em estudos científicos, trazer a discussão para a seara na qual ela precisa estar - a academia - faz-se essencial.

Sendo assim, a ideia em curso, no caso específico da exposição do memorial de formação, é tratar dos caminhos e escolhas implicados nas diversas dimensões que nos

\footnotetext{
1 Assinalo que a Educação Infantil é a primeira etapa da Educação Básica em nosso país e atende crianças de 0 a 5 anos de idade (BRASIL, 1996/ Redação dada pela Lei no 12.796, de 2013).
} 
formam e (con)formam (SARAT; CAMPOS, 2014). À luz do referencial teórico elisiano (ELIAS, 1994; 2001; 2011) e da abordagem (auto)biográfica em suas interfaces com o campo educativo (ABRAHÃO, 2011; SOUZA, 2006; 2007), no texto eu pretendo descrever e dialogar acerca das desigualdades socialmente construídas, buscando contribuir para o respeito à alteridade (GOUVÊA, 2011).

\title{
Trajetória em foco: evocando a memória
}

Para iniciar, importante que eu traga o excerto que segue:

\begin{abstract}
No ano de 2007 conhecemos uma estudante universitária que atendia pelo nome social de Satine. Ela nos apresentou a diferença/desigualdade concreta sentida na pele e no corpo de quem cotidianamente conviveu nos espaços de exclusão da educação, da escola, da rua e todos os demais lugares que frequentou. Por causa disso, e na luta para sair disso, Satine se dedicou a compreender as temáticas de gênero, diversidade, sexualidade, homossexualidade, transexualidade, transgeneralidade, a partir de leituras em diferentes campos e perspectivas (OLIVEIRA; CAMPOS, 2015, p. 91).
\end{abstract}

Sobre a citação, assinalo que ela contém praticamente todo o primeiro parágrafo do artigo Infância e gênero: Memorial de pesquisas, cuja publicação aconteceu no ano de 2015 pela Revista Retratos da Escola. Ele foi gestado com o objetivo de registrar e veicular os estudos e pesquisas realizados no bojo do Projeto de Pesquisa intitulado Histórias e Memórias de Infância: identidade de gênero na formação de profissionais da Educação Infantil (SARAT, 2008).

Para mim, é primordial referir-me à Satine (e eu faço isso em todas as oficinas, palestras e demais ações que desenvolvo), pois como escreveu Thiago de Mello, "o que passou não conta? Indagarão as bocas desprovidas. Não deixa de valer nunca. O que passou ensina com sua garra e seu mel"2. E conhecer e aprender acerca da temática de gênero e sexualidade e somá-la à minha trajetória de estudos da/na infância e educação infantil aconteceram, principalmente, devido ao encontro com ela.

No dizer de Elias (2001, p. 97), "[...] o fato de comunicar sentimentos a outras pessoas é uma das características primordiais da constituição do homem" e isto Satine sempre soube fazer muito bem, "[...] com sua garra e seu mel”.

Ela me afetou com sua história repleta de idiossincrasias, provocando não só um movimento que objetivou/objetiva apreensão de conhecimentos científicos, mas também um movimento que buscou/busca rever conceitos, preconceitos e vivências acerca de gênero e sexualidade no transcorrer da minha vida. Na percepção de Souza (2007, p. 65), "ao longo de seu percurso pessoal, consciente de suas idiossincrasias, o indivíduo constrói sua identidade pessoal mobilizando referentes que estão no coletivo. Mas, ao manipular esses referentes de forma pessoal e única, constrói subjetividades, também únicas".

\footnotetext{
2 Thiago de Mello em A vida verdadeira. Inclusa na obra Faz escuro mas eu canto. Disponível em: http://www.avozdapoesia.com.br/obras_ler.php?obra_id=12371. Acesso em: 2 fev. 2018.
} 
Nesse enquadramento, dar visibilidade ao meu memorial de formação implica externar uma "travessia" que, na perspectiva de Soares (1991), pode ser somada à História da Educação e, especificamente no meu caso, eu entendo que pode ser ampliada à História da Educação Infantil, Estudos de Gênero e, especialmente, História das Mulheres. Ou seja, é importante e necessário "[...] possibilitar a entrada dos sujeitos femininos no cenário historiográfico" (SARAT; CAMPOS, 2016, p. 10), levando em consideração as novas perspectivas de análises que têm expandido suas áreas de investigação, bem como incorporado novas metodologias.

Permito-me escrever, inspirada em Elias (2001, p. 10), quando ele declarou por ocasião das entrevistas concedidas a A. J. Heerna van Voss e A. van Stolkque que "[...] grande parte de minha vida concentrou-se em meu trabalho". Mas é notório que em muitas de suas obras o autor "[...] deixou transparecer como experiências intelectuais estavam intimamente relacionadas com as existenciais" (KIRSCHNER, 1999, p. 29).

E, ainda sobre essa perspectiva, escolho trazer Eliane Marta Teixeira Lopes, que ao escrever a introdução do livro Metamemória - Memórias: travessia de uma educadora assim se manifestou:

[...] é reconfortante constatar o fim dos tempos em que o autor [autora] desaparecia por trás dos discursos, e que a vida privada, o homem, a mulher, a criança, o aluno, o trabalhador, o professor se diluíam em categorias tão amplas que o sangue e a carne da História eram jogados fora como inúteis figurações (LOPES, 1991, p. 13, acréscimo meu).

Posto isto, continuando o meu propósito de abranger vida e trabalho em espirais que se somam e se espraiam ao mesmo tempo, provocando sentidos e significados, eu me reporto a Abrahão (2011, p. 166, grifos do original), para quem o memorial de formação é

[...] o processo e a resultante da rememoração com reflexão sobre fatos relatados, oralmente e/ou por escrito, mediante uma narrativa de vida, cuja trama (enredo) faça sentido para o sujeito da narração, com a intenção, desde que haja sempre uma intencionalidade, de clarificar e ressignificar aspectos, dimensões e momentos da própria formação.

A partir dessa exposição anterior, sigo destacando que estudar/pesquisar acerca de docência, Educação Infantil, gênero e sexualidade tem se constituído em minha aventura. Por conseguinte, importa eu voltar, no tempo e no espaço, para contar que trabalhar com professoras ${ }^{3}$ tem sido a tônica da minha profissão.

Sou graduada em Psicologia e desde a minha formação inicial efetivada na Faculdade de Filosofia e Ciências Humanas (FAFICH) da Universidade Federal de Minas Gerais (UFMG/1985), minha trajetória se estabeleceu junto à educação,

\footnotetext{
${ }^{3}$ A opção pela nomenclatura professoras vai ao encontro da presença quase unânime de mulheres no trabalho educativo com a infância, especialmente aqui me referindo às instituições públicas de educação infantil de Dourados/MS.
} 
especialmente a educação infantil, quando atuei como estagiária, e depois no trabalho com professoras já formadas exercendo as funções de psicóloga, coordenadora e diretora em uma instituição de atendimento das crianças de 0 a 6 anos na UFMG (19862002).

Nos últimos quatorze anos, eu atuei na formação inicial no curso de Pedagogia na Universidade Federal da Grande Dourados (UFGD) e na Universidade Estadual de Mato Grosso do Sul (UEMS) e, também, na formação continuada com muitas delas em diferentes ações desenvolvidas na cidade de Dourados e região, estado de Mato Grosso do Sul.

E foi exatamente na efetivação de um trabalho de formação continuada com professoras e coordenadoras da Educação Infantil, na Secretaria de Educação de Dourados (SEMED), no referido estado, desenvolvido nos anos 2006-2007, que se deu a definição pela minha pesquisa do/no Mestrado em Educação. Vale sinalizar que, exatamente nesse tempo e espaço, vivi a experiência de conhecer a Satine.

O Projeto de Extensão ${ }^{4}$ desenvolvido à época, nomeado Projeto Político Pedagógico na Educação Infantil: formação docente e elaboração do documento constituiu-se em grande provocação, principalmente quando entre as dificuldades de escritas das profissionais envolvidas surgiram esquivas, reticências, comedimentos e cuidados ao iniciarem os estudos com as temáticas de gênero e sexualidade. As expressões das professoras e coordenadoras indicavam um não saber e/ou não querersaber e/ou não poder-saber sobre o assunto (FOUCAULT, 2009).

Elas relatavam que não tinham vivenciado em suas formações iniciais em Pedagogia, estudos acerca da temática em questão. E como profissionais da/na educação infantil, nos demais cursos que empreenderam ao longo de suas trajetórias, especializações e pós-graduações, elas também não haviam vivenciado a problematização dos temas em pauta. Nesse contexto, percebi que muitas angústias que experienciavam no cotidiano do fazer pedagógico estavam latentes e se encaminhavam, às vezes, com grandes dificuldades. Elas se expressavam assim: "esse assunto eu não sei"; "sobre isso eu tenho que estudar"; "disso eu não entendo nada" (CAMPOS, 2010).

E maiores foram os silêncios, denotando o que Elias (2011) discorre acerca das mudanças ocorridas ao longo do processo civilizador. De acordo com o autor, "[...] uma associação mais forte de sexualidade com vergonha e embaraço, e a correspondente restrição ao comportamento, se espraia mais ou menos uniformemente na sociedade" (ELIAS, 2011, p. 172) e, portanto, o esclarecimento das questões relativas à sexualidade passa a ser um "problema agudo" nas relações entre adultos e crianças.

E seguindo com Elias (2011, p. 173, grifos meus), eu destaco:

[...] a sexualidade [...] é cada vez mais transferida para trás da cena da vida social e isolada em um enclave particular, a família nuclear. [...] Uma aura de embaraço, a manifestação de um medo sociogenético, cerca essa esfera da vida. Mesmo entre adultos é referida apenas com cautela e circunlóquios. E no caso de crianças, especialmente de meninas, essas coisas não são, tanto quanto possível, absolutamente mencionadas.

\footnotetext{
${ }^{4}$ Projeto de Extensão executado junto à Pró-Reitoria de Extensão e Cultura da Universidade Federal da Grande Dourados - PROEX/UFGD.
} 
Em vista "disso", e para tentar ir além "disso", propondo uma discussão acerca da temática de gênero e sexualidade e suas interfaces com a infância e a educação infantil, construí minha dissertação de mestrado - Memórias de infância de professoras da Educação Infantil: gênero e sexualidade (CAMPOS, 2010) ${ }^{5}$, cujo estudo integrou o Projeto de Pesquisa Histórias e Memórias de Infância: identidade de gênero na formação de profissionais da Educação Infantil (SARAT, 2008), já apontado anteriormente.

E neste tempo, ao escrever meu memorial de formação, me permito registrar que em minha vivência pessoal, e no decorrer de minha formação e atuação profissional até aquele momento [Mestrado em Educação, 2010], o trato com a temática se dava na perspectiva de que "[...] especialmente de [com] meninas, essas coisas não são, tanto quanto possível, absolutamente mencionadas" (ELIAS, 2011, p. 173, grifos e acréscimo meus).

Como explicita Belmira Oliveira Bueno no artigo $O$ método autobiográfico e os estudos com histórias de vida de professores: a questão da subjetividade, "[...] ao voltar-se para seu passado e reconstituir seu percurso de vida o indivíduo exercita sua reflexão e é levado a uma tomada de consciência tanto no plano individual como no coletivo" (BUENO, 2002, p. 23).

Importa refletir a citação da autora com Elias (1994), para quem a sociedade não existe para além dos indivíduos. Muito menos os indivíduos são seres humanos que vivem isolados. "A história é sempre história de uma sociedade, mas, sem a menor dúvida, de uma sociedade de indivíduos" (ELIAS, 1994, p. 45).

Nessa conjuntura, circunstanciando a pesquisa, assinalo que utilizei como fonte documentos produzidos a partir da transcrição de entrevistas semiestruturadas, realizadas com os construtos metodológicos da História Oral, quando foram compiladas memórias de infância de professoras da educação infantil.

A História Oral, considerada uma importante fonte para recolhimento dos dados empíricos, como apontou Alberti (2013, p. 31), “[...] decorre de toda uma postura com relação à história e às configurações socioculturais, que privilegia a recuperação do vivido conforme concebido por quem viveu". Tal metodologia é capaz de abrigar as histórias e memórias de grupos pequenos, dando "[...] sentido social às experiências vividas sob diferentes circunstâncias" (MEIHY, 2002, p. 10).

Por esse ângulo de discussão, recolhi as memórias de cinco mulheres nascidas nas décadas de 1960 e 1970, em Dourados, as quais tinham vivido suas infâncias na cidade. Ou seja, trabalhei com o entendimento da História Oral como uma metodologia inteirada com os debates de novas tendências da história contemporânea, cujo pressuposto supõe que o passado continua hoje e não constitui um processo histórico acabado, pois "[...] garante sentido à vida dos depoentes e leitores, que passam a entender a sequência histórica e se sentem parte do contexto em que vivem" (MEIHY, 2002, p. 15).

\footnotetext{
${ }^{5}$ Dissertação desenvolvida no Programa de Pós-Graduação em Educação na Faculdade de Educação, da Universidade Federal da Grande Dourados (PPGEdu/FAED/UFGD), sob a orientação da Prof. Dra. Magda Sarat.
} 
Avançando no relato acerca da investigação em foco, registro que elenquei como objetivo saber como as professoras, mulheres, pedagogas, profissionais da rede pública do município de Dourados (lócus da investigação), tinham vivenciado/construído concepções acerca de gênero e sexualidade nas suas diversas relações interpessoais, nos espaços privado e público, quer sejam nas suas famílias, com os amigos, os vizinhos, na escola e na igreja. Conforme aponta Xavier Filha (2005, p. 197), “[...] qualquer espaço social pode transformar-se em instâncias e práticas pedagógicas, desde que orientados para a constituição de sujeitos".

A partir das vozes das mulheres/professoras, as conclusões da pesquisa lançaram luz para histórias de diferenciação na educação de meninas e meninos, que as fizeram se sentir tolhidas, cerceadas, diminuídas socialmente, impossibilitadas de viverem as mesmas experiências que os irmãos, de não terem acesso a todas as informações $e$ espaços que eles tiveram, dentre outras (CAMPOS, 2010).

Ou seja, as mulheres/professoras lembraram que em suas infâncias, diferenças foram transformadas em desigualdades, reverberando uma ideia de que existem lugares que são naturalmente para as mulheres e, em contrapartida, lugares que são naturalmente para os homens. Compõe essa concepção, a perspectiva de uma essência feminina e uma essência masculina, divergindo do entendimento de que o gênero é uma construção social, cultural e histórica e que as relações entre mulheres e homens, como outras relações sociais, estão permeadas pelo poder (SCOTT, 1995).

Neste ponto de escrita do meu memorial de formação, eu vou ao encontro das Considerações Finais da Dissertação de Mestrado, pois na ocasião, escrevi como minha investigação havia pronunciado que "[...] muitos esforços continuam sendo necessários na empreitada e na luta pelo espaço de pensar, de expressar e de conviver com as diferenças. E que múltiplos estudos, discussões e pesquisas precisam ser realizados" (CAMPOS, 2010, p. 92).

E, em certa medida, posso afirmar que tomei tais palavras para mim, pois nos últimos dez anos transcorridos desde a minha defesa, eu tenho me empenhado em fazer valer e ampliar a ideia de "[...] um legado que virou pesquisa" (OLIVEIRA; CAMPOS, 2015, p. 91). Obviamente, é relevante demarcar, não sem dores e percalços, concordando com as perguntas de Constantina Xavier Filha, no artigo As dores e as delícias de trabalhar com as temáticas de gênero, sexualidades e diversidades na formação docente. A autora em questão nomeia suas angústias, elencando "como problematizar o discurso religioso? Como desestabilizar discursos preconceituosos, homofóbicos, sexistas e misóginos?” (XAVIER FILHA, 2012, p. 14).

Para avançar, eu retorno às reflexões de Souza (2006), quando o autor afirma que na perspectiva da "história de vida em formação", entende-se que se entrelaçam investigação e formação, na medida em que:

[...] configura-se como investigação porque se vincula à produção de conhecimentos experienciais dos sujeitos adultos em formação. Por outro lado, é formação porque parte do princípio de que o sujeito toma consciência de si e de suas aprendizagens experienciais quando vive, simultaneamente, os papéis de ator e investigador da sua própria história (SOUZA, 2006, p. 26). 
Por esse prisma, eu indico que retomei os caminhos trilhados até aqui, buscando apreender sobre o que aprendi ${ }^{6}$, como aprendi, por que aprendi e por quem aprendi. Para Larrosa Bondía (2002, p. 21), "a experiência é o que nos passa, o que nos acontece, o que nos toca. Não o que se passa, não o que acontece, ou o que toca. A cada dia se passam muitas coisas, porém, ao mesmo tempo, quase nada nos acontece". Então continuo, a seguir, respondendo ao objetivo do texto, quer seja, dar visibilidade ao memorial de formação da autora, trazendo a trajetória de trabalho com professoras.

\section{Ações em foco: formando e se formando}

Tocada por Larrosa Bondía (2002), a partir do movimento de visitar/rememorar o que "nos aconteceu", eu construí três Quadros, a saber: Quadro 1: A pesquisa de mestrado e seus desdobramentos; Quadro 2: Os trabalhos de orientação (TCC/TG/Iniciação Científica) e suas publicações; Quadro 3: Palestras, oficinas e outras ações. A escolha por este formato de exposição almeja contribuir para o conhecimento/entendimento das/os leitoras/es dos espaços e tempos de onde eu falo/escrevo e nos quais eu pretendo continuar para, a partir de outros olhares, possibilitar outros fazeres.

Quadro 1 - A pesquisa de mestrado e seus desdobramentos

\begin{tabular}{|c|c|c|c|}
\hline Autor & Título do trabalho & $\begin{array}{l}\text { Ano de } \\
\text { publicação }\end{array}$ & Evento/Periódico \\
\hline $\begin{array}{l}\text { - Magda Sarat } \\
\text { - Míria Izabel Campos }\end{array}$ & $\begin{array}{l}\text { Memórias de infância e identidade de } \\
\text { gênero na formação das profissionais } \\
\text { na educação infantil }\end{array}$ & 2008 & $\begin{array}{ll}\text { Seminário } & \text { Internacional } \\
\text { Fazendo Gênero } & \end{array}$ \\
\hline $\begin{array}{l}\text { - Míria Izabel Campos } \\
\text { - Magda Sarat }\end{array}$ & $\begin{array}{l}\text { Gênero e sexualidade: infância e } \\
\text { educação infantil em questão }\end{array}$ & 2009 & $\begin{array}{l}\text { III Seminário de Pesquisa da } \\
\text { FAED/UFGD }\end{array}$ \\
\hline $\begin{array}{l}\text { - Míria Izabel Campos } \\
\text { - Magda Sarat }\end{array}$ & $\begin{array}{l}\text { Gênero e sexualidade na formação de } \\
\text { professoras da educação infantil }\end{array}$ & 2010 & $\begin{array}{l}\text { X Encontro de Pesquisa da } \\
\text { ANPEd Centro Oeste }\end{array}$ \\
\hline - Míria Izabel Campos & $\begin{array}{l}\text { Civilidade, gênero e } \text { sexualidade: } \\
\text { memórias de espaços } \\
\text { privados }\end{array}$ & 2012 & $\begin{array}{l}\text { Capítulo no livro "Sobre } \\
\text { processos civilizadores: diá- } \\
\text { logos com Norbert Elias" }\end{array}$ \\
\hline $\begin{array}{l}\text { - Magda Sarat } \\
\text { - Míria Izabel Campos }\end{array}$ & $\begin{array}{l}\begin{array}{l}\text { Gênero, sexualidade } \\
\text { (Con)formando meninas }\end{array} \\
\end{array}$ & 2014 & $\begin{array}{l}\text { Revista Tempos e Espaços em } \\
\text { Educação }\end{array}$ \\
\hline $\begin{array}{l}\text { - Magda Carmelita } \\
\text { Sarat Oliveira } \\
\text { - Míria Izabel Campos }\end{array}$ & $\begin{array}{l}\text { Infância e gênero: memorial de pesqui- } \\
\text { sas }\end{array}$ & 2015 & Revista Retratos da Escola \\
\hline $\begin{array}{l}\text { - Magda Sarat } \\
\text { - Míria Izabel Campos }\end{array}$ & $\begin{array}{l}\text { Itinerários docentes na educação } \\
\text { infantil: olhares sobre gênero nas } \\
\text { memórias de professoras }\end{array}$ & 2016 & $\begin{array}{l}\text { XI Congresso Luso-Brasileiro } \\
\text { da História da Educação }\end{array}$ \\
\hline - Míria Izabel Campos & $\begin{array}{l}\text { Trajetórias docentes: olhares sobre } \\
\text { gênero nas memórias de infância de } \\
\text { professoras }\end{array}$ & 2016 & $\begin{array}{l}\text { VII Congresso Internacional de } \\
\text { Pesquisa (Auto) Biográfica } \\
\text { (VII CIPA) }\end{array}$ \\
\hline - Míria Izabel Campos & $\begin{array}{l}\text { Gênero e sexualidade no Projeto Po- } \\
\text { lítico Pedagógico da Educação Infantil: } \\
\text { pesquisas no MS - 2012/2016 }\end{array}$ & 2016 & $\begin{array}{l}\text { Encontro de } \text { Pesquisa em } \\
\text { Educação da Região Centro } \\
\text { Oeste - ANPEd }\end{array}$ \\
\hline
\end{tabular}

\footnotetext{
${ }^{6}$ Utilizo-me do título da Seção I das Notas biográficas, contidas na obra Norbert Elias por ele mesmo (2001).
} 


\begin{tabular}{|l|l|c|l|}
\hline $\begin{array}{l}\text { - Magda Sarat } \\
\text { - Míria Izabel Campos }\end{array}$ & $\begin{array}{l}\text { Memórias da infância e da educação: } \\
\text { abordagens elisianas sobre as mulheres }\end{array}$ & 2017 & Revista Educação \& Realidade \\
\hline - Míria Izabel Campos & $\begin{array}{l}\text { Homens na pedagogia? Discutindo } \\
\text { relações de gênero e poder a partir de } \\
\text { memoriais de infância - Dourados/MS }\end{array}$ & 2018 & $\begin{array}{l}17^{\circ} \text { Simpósio Internacional } \\
\text { Processos } \\
\text { "Processos Civilizadores } \\
\text { Históricos, Políticos, Sociais e } \\
\text { Educativos" }\end{array}$ \\
\hline $\begin{array}{l}\text {-Juliana da Silva } \\
\text { Lourenção } \\
\text { - Míria Izabel Campos }\end{array}$ & $\begin{array}{l}\text { Gênero, Sexualidade e Educação } \\
\text { Infantil: Formação na Universidade }\end{array}$ & 2018 & $\begin{array}{l}\text { V Congresso de Educação da } \\
\text { Grande Dourados: escola } \\
\text { brasileira no contexto das } \\
\text { reformas do século XXI }\end{array}$ \\
\hline $\begin{array}{l}\text { - Adaiane Enequio } \\
\text { Palhano }\end{array}$ & $\begin{array}{l}\text { Mocência e Gênero na Formação } \\
\text { - Izabel Campos } \\
\text { Histórias para Ede Homens na Pedagogia- } \\
\text { Dourados/MS }\end{array}$ & 2019 & $\begin{array}{l}\text { V EHECO Memória e } \\
\text { Democracia: Os tempos e os } \\
\text { espaços da História da } \\
\text { Educação }\end{array}$ \\
\hline - Míria Izabel Campos & $\begin{array}{l}\text { Projeto Político Pedagógico da } \\
\text { Educação Infantil: olhares para gênero } \\
\text { e sexualidade no documento-MS } \\
\text { (2012-2019) }\end{array}$ & 2019 & $\begin{array}{l}\text { SemiEdu 2019 - Debates sobre } \\
\text { educação, pesquisa e inovação }\end{array}$ \\
\hline
\end{tabular}

Fonte: Campos, 2017. Reelaboração da autora

Quadro 2 - Os trabalhos de orientação (TCC/TG/Iniciação Científica) e suas publicações

\begin{tabular}{|c|c|c|c|}
\hline Autoras & Título do trabalho & $\begin{array}{c}\text { Ano da } \\
\text { defesa/ } \\
\text { Publicação }\end{array}$ & Universidade/Periódico \\
\hline $\begin{array}{l}\text { - Ivanete Fernandes } \\
\text { Pereira } \\
\text {-Míria Izabel Campos }\end{array}$ & $\begin{array}{l}\text { Formação da identidade de gênero na } \\
\text { instituição de educação infantil: } \\
\text { expressões e falas das crianças }\end{array}$ & 2011 & $\begin{array}{l}\text { Especialização em Educação } \\
\text { Infantil /UEMS/ Dourados }\end{array}$ \\
\hline $\begin{array}{l}\text { - Ana Lúcia de Oliveira } \\
\text { Campos } \\
\text { - Míria Izabel Campos }\end{array}$ & $\begin{array}{l}\text { Construção de identidade de gênero } \\
\text { na educação infantil: filmes infantis } \\
\text { ensinando a ser menina e menino }\end{array}$ & 2011 & $\begin{array}{lll}\text { Graduação } & \text { em } & \text { Pedagogia } \\
\text { /UFGD } & & \end{array}$ \\
\hline $\begin{array}{l}\text { - Amanda Serrano } \\
\text { Gonçalves } \\
\text { - Míria Izabel Campos }\end{array}$ & $\begin{array}{l}\text { Gênero e sexualidade no Projeto } \\
\text { Político Pedagógico da Educação } \\
\text { Infantil: um estudo em instituições } \\
\text { públicas de Dourados-MS }\end{array}$ & 2012 & $\begin{array}{l}\text { Graduação em Pedagogia } \\
\text { /UFGD }\end{array}$ \\
\hline $\begin{array}{l}\text { - Glauce Hoffmeister } \\
\text { dos Santos } \\
\text { - Míria Izabel Campos }\end{array}$ & $\begin{array}{l}\text { Brincadeiras nas instituições de } \\
\text { educação infantil: uma reflexão } \\
\text { acerca das relações de gênero e } \\
\text { sexualidade Dourados/MS }\end{array}$ & 2012 & $\begin{array}{l}\text { Graduação em Pedagogia } \\
\text { /UFGD }\end{array}$ \\
\hline $\begin{array}{l}\text { - Bianca Camacho de } \\
\text { Almeida Böhm • Míria } \\
\text { Izabel Campos }\end{array}$ & $\begin{array}{l}\text { Atuação de professores homens na } \\
\text { educação básica: um estado da arte } \\
\text { sobre a produção acadêmica }\end{array}$ & 2013 & $\begin{array}{l}\text { Graduação em } \\
\text { Pedagogia/UFGD e publicação } \\
\text { na Horizontes Revista de } \\
\text { Educação }\end{array}$ \\
\hline $\begin{array}{l}\text { - Joice Miriam Gassen } \\
\text { de Bona } \\
\text { - Míria Izabel Campos }\end{array}$ & $\begin{array}{l}\text { Gênero nas interações de crianças e } \\
\text { adultos: estudo em um Centro In- } \\
\text { tegrado de Educação Infantil - } \\
\text { Maracaju/MS }\end{array}$ & 2013 & $\begin{array}{l}\text { Graduação em Pedagogia } \\
\text { /UEMS/Maracaju }\end{array}$ \\
\hline $\begin{array}{l}\text { Rosimeire de Souza } \\
\text { Limonge • Míria Izabel } \\
\text { Campos } \\
\end{array}$ & $\begin{array}{l}\text { Relações de gênero nas brincadeiras } \\
\text { infantis: um estudo em instituição } \\
\text { pública - Maracaju/MS }\end{array}$ & 2013 & $\begin{array}{lll}\text { Graduação em } & \text { Pedagogia } \\
\text { /UEMS/Maracaju } & \end{array}$ \\
\hline $\begin{array}{l}\text { - Elizabeth Carvalho } \\
\text { da Silva } \\
\text { - Míria Izabel Campos }\end{array}$ & $\begin{array}{l}\text { Gênero e sexualidade na Educação } \\
\text { Infantil: estudo com professoras da } \\
\text { rede pública - Dourados/MS }\end{array}$ & 2014 & $\begin{array}{lll}\text { Graduação } & \text { em } & \text { Pedagogia } \\
\text { /UFGD } & & \end{array}$ \\
\hline - Georgia Daniela & Gênero e sexualidade no Projeto & 2014 & Graduação \\
\hline
\end{tabular}




\begin{tabular}{|c|c|c|c|}
\hline $\begin{array}{l}\text { Paliano Souza Silva } \\
\text { - Míria Izabel Campos }\end{array}$ & $\begin{array}{l}\text { Político Pedagógico: estudo em } \\
\text { instituições públicas de educação } \\
\text { infantil- } \\
\text { Maracaju/MS }\end{array}$ & & /UEMS/Maracaju \\
\hline $\begin{array}{l}\text { - Lethicia Ormedo } \\
\text { Leite Canhete } \\
\text { - Míria Izabel Campos }\end{array}$ & $\begin{array}{l}\text { Filmes infantis: o que ensinam para } \\
\text { meninas e meninos }\end{array}$ & 2014 & $\begin{array}{lll}\text { Graduação em } & \text { Pedagogia/ } \\
\text { UEMS/Maracaju } & \end{array}$ \\
\hline $\begin{array}{l}\text { - Ivanete Fernandes } \\
\text { Pereira } \\
\text { - Míria Izabel Campos }\end{array}$ & $\begin{array}{l}\text { Surgimento das instituições de } \\
\text { atendimento à criança e à mulher } \\
\text { trabalhadora: uma relação histórica }\end{array}$ & & $\begin{array}{l}\text { Publicação Horizontes Revista } \\
\text { de Educação a partir da } \\
\text { Especialização em Educação } \\
\text { Infantil / UEMS /Dourados }\end{array}$ \\
\hline $\begin{array}{l}\text { - Elis Kedma Teodoro } \\
\text { da Silva } \\
\text { - Míria Izabel Campos }\end{array}$ & $\begin{array}{l}\text { Gênero e sexualidade nas brinca- } \\
\text { deiras de faz de conta: estudo com } \\
\text { professoras da educação infantil - } \\
\text { Maracaju/MS }\end{array}$ & 2015 & $\begin{array}{l}\text { Graduação em } \text { Pedagogia/ } \\
\text { UEMS/Maracaju }\end{array}$ \\
\hline $\begin{array}{l}\text { - Miguela Célia Correa } \\
\text { de Oliveira } \\
\text { - Míria Izabel Campos }\end{array}$ & $\begin{array}{l}\text { Gênero e sexualidade na Educação } \\
\text { Infantil: Projeto Político Pedagógico } \\
\text { e práticas cotidianas nas instituições }\end{array}$ & 2016 & $\begin{array}{l}\text { Especialização em Docência na } \\
\text { Educação Infantil /UFGD }\end{array}$ \\
\hline $\begin{array}{l}\text { - Edilaine de Mello } \\
\text { Macedo } \\
\text { - Magda Sarat } \\
\text { - Míria Izabel Campos }\end{array}$ & $\begin{array}{l}\text { Infância, gênero, brinquedos e } \\
\text { brincadeiras de meninos e meninas }\end{array}$ & 2016 & Científica/PIBIC- \\
\hline $\begin{array}{l}\text { - Magda Sarat } \\
\text { - Míria Izabel Campos } \\
\text { - Edilaine de Mello } \\
\text { Macedo }\end{array}$ & $\begin{array}{l}\text { Infância, gênero, brinquedos e brin- } \\
\text { cadeiras de meninos e meninas }\end{array}$ & 2016 & $\begin{array}{l}\text { Publicação Horizontes Revista } \\
\text { de Educação }\end{array}$ \\
\hline $\begin{array}{l}\text { - Adaiane Enequio } \\
\text { Palhano } \\
\text { - Míria Izabel Campos }\end{array}$ & $\begin{array}{l}\text { Infância e diversidades } \\
\text { sexuais/diferenças nas brincadeiras e } \\
\text { nos brinquedos de meninas e meninos }\end{array}$ & 2017 & $\begin{array}{l}\text { Iniciação } \quad \text { Científica/PIBIC- } \\
\text { UFGD }\end{array}$ \\
\hline $\begin{array}{l}\text { Edilaine de Mello } \\
\text { Macedo } \\
\text { - Míria Izabel Campos }\end{array}$ & $\begin{array}{l}\text { Gênero e sexualidade nas brinca- } \\
\text { deiras e nos brinquedos de meninas e } \\
\text { meninos: estudo na educação infantil } \\
\text { - Indápolis/MS }\end{array}$ & 2017 & $\begin{array}{lll}\text { Graduação } & \text { em } & \text { Pedagogia } \\
\text { /UFGD } & & \end{array}$ \\
\hline $\begin{array}{l}\text {-Juliana da Silva } \\
\text { Lourenção } \\
\text { - Míria Izabel Campos }\end{array}$ & $\begin{array}{l}\text { Gênero, Sexualidade e Educação } \\
\text { Infantil: formação e práticas } \\
\text { pedagógicas de professoras }\end{array}$ & 2018 & $\begin{array}{lll}\text { Graduação } & \text { em } & \text { Pedagogia } \\
\text { /UFGD } & & \end{array}$ \\
\hline $\begin{array}{l}\text { Adaiane Enequio } \\
\text { Palhano } \\
\text { - Míria Izabel Campos }\end{array}$ & $\begin{array}{l}\text { Memoriais de infância do homem } \\
\text { pedagogo: trajetórias em uma } \\
\text { profissão feminina }\end{array}$ & 2018 & Científica/PIBIC- \\
\hline $\begin{array}{l}\text { - Adaiane Enequio } \\
\text { Palhano } \\
\text { - Míria Izabel Campos }\end{array}$ & $\begin{array}{l}\text { Homens na Educação Infantil em } \\
\text { Dourados/MS: docência e gênero }\end{array}$ & 2018 & $\begin{array}{lll}\text { Graduação } & \text { em } & \text { Pedagogia } \\
\text { /UFGD } & & \end{array}$ \\
\hline $\begin{array}{l}\text {-Janaina Dorneles } \\
\text { Torres } \\
\text { - Míria Izabel Campos }\end{array}$ & $\begin{array}{l}\text { Gênero e Sexualidade no Projeto } \\
\text { Político Pedagógico da Educação } \\
\text { Infantil - Itaporâ/MS }\end{array}$ & 2019 & Científica/PIBIC- \\
\hline $\begin{array}{l}\text { - Daiane Joice } \\
\text { Schuindt Fernandes } \\
\text { - Míria Izabel Campos }\end{array}$ & $\begin{array}{l}\text { Histórias da educação feminina em } \\
\text { memoriais de infância: geração e } \\
\text { gênero na família e na escola }\end{array}$ & 2019 & Científica/PIBIC- \\
\hline $\begin{array}{l}\text {-Janaina Dorneles } \\
\text { Torres } \\
\text { - Míria Izabel Campos }\end{array}$ & $\begin{array}{l}\text { Gênero, Sexualidade e Educação } \\
\text { Infantil: um olhar para as práticas } \\
\text { cotidianas-Itaporã/MS }\end{array}$ & 2019 & $\begin{array}{lll}\text { Graduação } & \text { em } & \text { Pedagogia } \\
\text { /UFGD } & & \end{array}$ \\
\hline
\end{tabular}

Fonte: Campos, 2017. Reelaboração da autora

Quadro 3 - Palestras, oficinas e outras ações 


\begin{tabular}{|c|c|c|c|}
\hline Autoras & Título do trabalho & $\begin{array}{c}\text { Ano } \\
\text { Apresentaçã } \\
\text { o } \\
\end{array}$ & Evento/Projeto \\
\hline - Míria Izabel Campos & $\begin{array}{l}\text { Palestra: Gênero, sexualidade e infân- } \\
\text { cia: "descobrindo e redescobrindo } \\
\text { significados" }\end{array}$ & 2011 & $\begin{array}{lll}\text { Círculo } & \text { de } & \text { palestras } \\
\text { OMEP/UNIGRAN/ } & \\
\text { Dourados } & & \end{array}$ \\
\hline - Míria Izabel Campos & $\begin{array}{l}\text { Discutindo práticas educacionais na } \\
\text { educação infantil: brincadeira de } \\
\text { menina ou de menino? }\end{array}$ & 2011 & 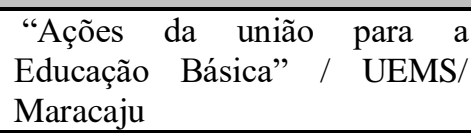 \\
\hline $\begin{array}{l}\text { - Míria Izabel Campos } \\
\text { - Magda Sarat }\end{array}$ & $\begin{array}{l}\text { Pesquisa em educação infantil: } \\
\text { gênero e sexualidade na memória de } \\
\text { infância das professoras }\end{array}$ & 2012 & $\begin{array}{l}\text { IV Jornada Nacional de } \\
\text { Educação de Naviraí / UFMS } \\
\text { /Naviraí }\end{array}$ \\
\hline - Míria Izabel Campos & $\begin{array}{l}\text { Gênero, sexualidade e e educação } \\
\text { infantil: "descobrindo e eres- } \\
\text { cobrindo significados" }\end{array}$ & 2014 & $\begin{array}{l}\text { Centro } \quad \text { Universitário } \\
\text { Anhanguera/Campo Grande }\end{array}$ \\
\hline - Míria Izabel Campos & $\begin{array}{l}\text { Palestra: Relações de gênero e } \\
\text { diversidade sexual na escola }\end{array}$ & 2014 & $\begin{array}{l}\text { VII Seminário do Programa de } \\
\text { Educação Inclusiva - direito à } \\
\text { diversidade /SEMED/SECADI } \\
\text { /MEC/Dourados }\end{array}$ \\
\hline - Míria Izabel Campos & $\begin{array}{l}\text { Oficina: Gênero, sexualidade e } \\
\text { educação infantil: discutindo práticas } \\
\text { cotidianas e ações pedagógicas }\end{array}$ & 2015 & $\begin{array}{l}\text { V Encontro de Pedagogia do } \\
\text { MS. I Encontro de Iniciação à } \\
\text { Docência } \\
\text { Pedagogia/UEMS/Dourados } \\
\end{array}$ \\
\hline - Míria Izabel Campos & $\begin{array}{llrr}\text { Gênero, } & \text { sexualidade } & \text { e } & \text { educação } \\
\text { infantil: "descobrindo } & \text { e } & \text { redesco- } \\
\text { brindo significados" } & & \\
\end{array}$ & 2015 & $\begin{array}{l}1^{\circ} \text { Congresso de Educação da } \\
\text { Grande Dourados/UFGD }\end{array}$ \\
\hline $\begin{array}{l}\text { - Míria Izabel Campos } \\
\text { - Joice Camila dos } \\
\text { Santos Kochi }\end{array}$ & $\begin{array}{l}\text { Práticas pedagógicas na educação in- } \\
\text { fantil: gênero e sexualidade }\end{array}$ & 2016 & $\begin{array}{l}\text { "Brincadeira de criança: dis- } \\
\text { cutindo práticas pedagógicas e } \\
\text { formação docente" / UFMS } \\
\text { /Naviraí. }\end{array}$ \\
\hline $\begin{array}{l}\text {-Míria Izabel Campos } \\
\text { - Joice Camila dos } \\
\text { Santos Kochi }\end{array}$ & $\begin{array}{l}\text { Gênero, sexualidade e educação } \\
\text { infantil }\end{array}$ & 2016 & $\begin{array}{l}\text { PROJETO EDUCA MS } \\
\text { Centro de Educação Infantil / } \\
\text { CEI / UFGD/Dourados }\end{array}$ \\
\hline $\begin{array}{l}\text { - Míria Izabel Campos } \\
\text { - Joice Camila dos } \\
\text { Santos Kochi }\end{array}$ & $\begin{array}{l}\text { Gênero, sexualidade e educação } \\
\text { infantil }\end{array}$ & 2016 & $\begin{array}{l}\text { PROJETO EDUCA MS - } \\
\text { Escola Municipal Frei Eucário } \\
\text { Schmitt/Dourados }\end{array}$ \\
\hline $\begin{array}{l}\text { - Míria Izabel Campos } \\
\text { - Joice Camila dos } \\
\text { Santos Kochi }\end{array}$ & $\begin{array}{l}\text { Relações de gênero e diversidade } \\
\text { sexual na escola: discutindo práticas } \\
\text { cotidianas e ações pedagógicas }\end{array}$ & 2017 & $\begin{array}{l}\text { Projeto Bases teóricas } \\
\text { práticas pedagógicas para a } \\
\text { inclusão escolar- } \\
\text { Escola Estadual Professor } \\
\text { Alício Araújo/Dourados }\end{array}$ \\
\hline - Míria Izabel Campos & $\begin{array}{l}\text { Gênero, sexualidade e educação } \\
\text { infantil }\end{array}$ & 2017 & $\begin{array}{l}\text { PROJETO EDUCA MS - } \\
\text { Escola Municipal Professora } \\
\text { Efantina de Quadros/Dourados }\end{array}$ \\
\hline - Míria Izabel Campos & Educação infantil e gênero & 2018 & 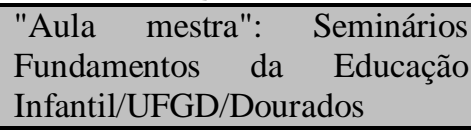 \\
\hline - Míria Izabel Campos & $\begin{array}{l}\text { Gênero e sexualidade na educação } \\
\text { infantil }\end{array}$ & 2018 & $\begin{array}{l}\text { Diálogo no } \\
\text { GEPEIND/Dourados }\end{array}$ \\
\hline - Míria Izabel Campos & $\begin{array}{l}\text { Gênero e sexualidade na docência da } \\
\text { educação infantil }\end{array}$ & 2018 & $\begin{array}{l}\text { XIII Semana Acadêmica do } \\
\text { Curso de Pedagogia - UEMS/ } \\
\text { Maracaju }\end{array}$ \\
\hline - Míria Izabel Campos & $\begin{array}{l}\text { Corpos oprimidos: reflexões sobre } \\
\text { violências de gênero }\end{array}$ & 2019 & $\begin{array}{l}\text { (R)Exista semana da mulher - } \\
\text { IFMS/Ponta Porã/MS }\end{array}$ \\
\hline - Míria Izabel Campos & $\begin{array}{l}\text { Gênero e formação para docência na } \\
\text { educação infantil: desafios de uma }\end{array}$ & 2019 & $\begin{array}{lr}\text { Cátedra } & \text { UNESCO/UFGD - } \\
\text { Gênero, Diversidade Cultural e }\end{array}$ \\
\hline
\end{tabular}




\begin{tabular}{|l|l|c|l|}
\hline & trajetória & & $\begin{array}{l}\text { Fronteiras } \\
\text { FCH/UFGD/Dourados }\end{array}$ \\
\hline - Míria Izabel Campos & $\begin{array}{l}\text { Educação Infantil e gênero: direito de } \\
\text { ser menina e ser menino do jeito que } \\
\text { quiser }\end{array}$ & 2019 & $\begin{array}{l}\text { VII Semana Acadêmica de } \\
\text { Ciências Sociais - } \\
\text { FCH/UFGD/Dourados }\end{array}$ \\
\hline
\end{tabular}

Fonte: Campos, 2018. Reelaboração da autora

\section{CONSIDERAÇÕES FINAIS}

Como nos alerta Gouvêa (2011, p. 549), "na produção histórica da modernidade, emerge como central o apagamento da alteridade [...]", o que, em meu entendimento, pode provocar um movimento discriminatório de consequências aterradoras. Nesse sentido, percebo como primordial expor e dialogar acerca das desigualdades socialmente construídas, pois todas as diversidades, ou seja, geração, gênero, orientação sexual, raça, etnia, classe carecem de serem desnaturalizadas, para efetivamente ser possível escrevermos outras Histórias - História da Educação, História da Educação Infantil, Estudos de Gênero, História das Mulheres.

Como já referido anteriormente, a partir dos trabalhos apresentados, eu tenho a expectativa de mobilizar e incentivar a realização de mais pesquisas relacionadas à temática em questão, bem como fomentar a necessidade de se prosseguir com estudos sobre gênero e sexualidade na formação docente, possibilitando ampliar discussões e debates nos diferentes contextos de educação, da comunidade e demais espaços sociais.

\section{REFERÊNCIAS}

ABRAHÃO, M. H. M. B. Memoriais de formação: a (re)significação das imagens lembranças/recordações-referências para a pedagoga em formação. Educação, Porto Alegre, v. 34, n. 2, p. 165-172, maio/ago. 2011.

ALBERTI, V. Manual de História Oral. 3. ed. Rio de Janeiro: Editora FGV, 2013.

BRASIL. LEI No 9.394, DE 20 DE DEZEMBRO DE 1996. Estabelece as diretrizes e bases da educação nacional. http://www.planalto.gov.br/ccivil_03/leis/19394.htm. Acesso em: 03 mar. 2019.

BUENO, B. O. O método autobiográfico e os estudos com histórias de vida de professores: a questão da subjetividade. Educação e Pesquisa, São Paulo, v.28, n .1, p. 11-30, jan./jun. 2002.

CAMPOS, M. I. Memórias de infância de professoras da educação infantil: gênero e sexualidade. 2010. 122 f. Dissertação (Mestrado em Educação) -Universidade Federal da Grande Dourados/UFGD, Dourados, 2010. 
ELIAS, N. A sociedade dos indivíduos. Organizado por Michael Schröter. Tradução Vera Ribeiro. Revisão técnica e notas Renato Janine Ribeiro. Rio de Janeiro: Zahar, 1994.

ELIAS, N. Norbert Elias por ele mesmo. Tradução André Telles. Rio de Janeiro: Zahar, 2001.

ELIAS, N. O processo civilizador, volume 1: uma história dos costumes. 2. ed. Tradução Ruy Jungmann. Revisão e apresentação Renato Janine Ribeiro. Rio de Janeiro: Zahar, 2011.

FOUCAULT, M. História da sexualidade I: A vontade de saber. Trad. Maria Thereza da Costa Albuquerque. 19. ed. Rio de Janeiro: Graal, 2009.

GOUVÊA, M. C. S. Infantia: entre a anterioridade e a alteridade. Educ. Real., Porto Alegre, v. 36, n. 2, p. 547-567, maio/ago. 2011. Disponível em:

<http://www.ufrgs.br/edu_realidade>. Acesso em: 18 jun. 2017.

KIRSCHNER, T. C. Lembrando Norbert Elias. Textos de História, v. 7, n. 1/2, 1999.

LARROSA BONDÍA, J. Notas sobre a experiência e o saber de experiência. Tradução de João Wanderley Geraldi. Revista Brasileira de Educação. jan./fev./mar./abr. n. 19, p. 20-28, 2002.

LOPES, E. M. T. Introdução. In: SOARES, M. Metamemória-Memórias: travessia de uma educadora. São Paulo: Cortez, 1991. (Coleção Educação Contemporânea. Série Memória da Educação).

MEIHY, J. C S. B. Manual de história oral. 4. ed. São Paulo: Loyola, 2002.

OLIVEIRA, M. C. S; CAMPOS, M. I. Infância e gênero: memorial de pesquisas. Retratos da Escola, Brasília, v. 9, n. 16, p. 91-110, jan./jun. 2015. Disponível em: <http//www.esforce.org.br>. Acesso em: 10 out. 2017.

SARAT, M. Projeto de Pesquisa "Histórias e Memórias de Infância: identidade de gênero na formação de profissionais da Educação Infantil". UFGD/PROPP. Dourados, 2008. 
.; CAMPOS, M. I. Gênero, sexualidade e infância: (Con)formando meninas. Revista Tempos e Espaços em Educação. v. 7, n. 12, jan./abr. 2014. Disponível em: <https://seer.ufs.br/index.php/revtee/article/view/2951>. Acesso em: 1 mar. 2015.

.; CAMPOS, M. I. Itinerários docentes na educação infantil: olhares sobre gênero nas memórias de professoras. XI Congresso Luso-Brasileiro da História da Educação (XI COLUBHE). Porto/Portugal. GT Investigar, Intervir e Preservar Caminhos da História da Educação Luso Brasileira. Anais..., 2016. p. 164-175.

SCOTT, J. Gênero: uma categoria útil de análise histórica. Educação \& Realidade, Porto Alegre, v. 20, n. 2, p. 71-99, jul./dez. 1995. Disponível em:

<https://seer.ufrgs.br/educacaoerealidade/article/view/71721>. Acesso em: 09 set. 2017.

SOARES, M. Metamemória-Memórias: Travessia de uma educadora. São Paulo: Cortez, 1991. (Coleção Educação Contemporânea. Série Memória da Educação).

SOUZA, E. C. A arte de contar e trocar experiências: reflexões teórico-metodológicas sobre história de vida em formação. Revista Educação em Questão, Natal, v. 25, n. 11, p. 22-39, jan./abr., 2006.

(Auto)biografia, histórias de vida e práticas de formação. In: NASCIMENTO, A. D.; HETKOWSKI, T. M. (Orgs.). Memória e formação de professores [online]. Salvador: EDUFBA, 2007.

XAVIER FILHA, C. Discursos da intimidade: imprensa feminina e narrativa de mulheres-professoras brasileiras e portuguesas na segunda metade do século XX. 2005. 354 f. Tese (Doutorado em Educação) - Faculdade de Educação, Universidade de São Paulo/ FEUSP/USP. São Paulo, 2005.

As dores e as delícias de trabalhar com as temáticas de gênero, sexualidades e diversidades na formação docente. In: SOUZA, L. L, de; ROCHA, S. A. da (Orgs.). Formação de educadores, gênero e diversidade. Cuiabá: EdUFMT, 2012. p.13-30. Coleção Gênero e Diversidade.

Recebido em: 23/05/2019

Aprovado em: 26/07/2019 